\title{
Is There a Guarantee That the Crisis of COVID-19 Will not Be Repeated?
}

\author{
Gholamreza Farnoosh, PhD; Sadegh Zarei, PhD; Solmaz Sadat Hosseini Zijoud, PhD; \\ Seyed Reza Hosseini Zijoud, PhD (1)
}

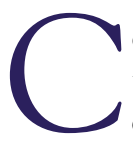

oronavirus disease 2019 (COVID-19) is the third known zoonotic beta coronavirus disease, after severe acute respiratory syndrome (SARS) and Middle East respiratory syndrome (MERS), that has emerged in recent years. Severe acute respiratory syndrome coronavirus (SARS-CoV) and Middle East respiratory syndrome coronavirus (MERS-CoV) may have originated in bats, as the main natural reservoir, and were transmitted to humans through the intermediate hosts of civet and camels, respectively. Epidemiological surveys of early cases of COVID-19 pneumonia in China showed that SARS-CoV-2 may also originate in bats and then be transmitted to humans by means of an intermediate host, pangolins, in the Huanan seafood market. ${ }^{1,2}$

After the closure of the Huanan seafood market, the virus outbreak has not stopped. COVID-19 has spread by human-to-human transmission around the world quickly and was declared a pandemic by the World Health Organization (WHO) on March 11, 2020. ${ }^{3}$ As of March 27, the populations of 199 countries worldwide have contracted the disease, with approximately 600,000 affected cases and 27,000 deaths (4.5\% mortality rate). ${ }^{4}$ The disease crisis has placed millions of people under quarantine as countries battle to contain the spread of SARS-CoV-2. It also caused enormous economic, social, cultural, and even psychological damage to different sectors of society. ${ }^{5}$

There are no antiviral treatments or vaccines for COVID19 infections as of March 2020, and the production of safe and stable vaccines and effective drugs is a long process. ${ }^{6}$ So, according to $\mathrm{WHO}$, the best way to deal with COVID-19 infection is control and prevention. ${ }^{7}$ However, given that the probable origin of COVID-19 has been animal consumption, it seems further efforts are needed. A logical next step must include implementation of stricter rules on food hygiene and food consumption in the world, which may prevent future crises.

International communities and organizations have strict rules against atomic bombs, chemical and biological weapons, wars, and many other traumatic events, and all are more or less adhering to the rules; however, there are no such international rules on food consumption, although a few countries have their own rules. ${ }^{8,9}$ Therefore, there is no guarantee that, in the coming years, the consumption of another animal will not lead to the creation of a pandemic and endanger human lives around the world.

So, perhaps the first and best way to prevent the spread of these contagious and deadly diseases is to modify and correct the food culture worldwide. There is a need for international communities, especially in global health, to plan and implement strategies, rules, and guidelines on food habits and food consumption to prevent the recurrence of such diseases as COVID-19. Such countries and organizations that have successful experiences in food consumption can take part.

Consider the rules on the prohibition of the certain foods, food preparation, food storing and cooking, and eating raw animal foods. The use of new and safe technologies, such as the use of probiotics and probiotic foods, can be helpful, and the consumption of herbal foods (vegan food) can also be considered.

The recurrence of pandemic diseases, such as COVID-19, in the coming years is possible to occur unless stricter laws on food consumption and the correction of people's eating habits are implemented. A recurrence not only affects 1 person or 1 country, but can challenge the entire world, and not only put the health sector at risk, but also overshadow all sectors, including the world economy and even people's jobs and livelihoods. So, it seems wise to pay attention to this warning.

\section{About the Authors}

Applied Biotechnology Research Center, Baqiyatallah University of Medical Sciences, Tehran, Iran (Dr Farnoosh); School of Medicine, Rafsanjan University of Medical Sciences, Rafsanjan, Iran (Dr Zarei); School of Public Health, Iran University of Medical Sciences, Tehran, Iran (Dr Hosseini Zijoud); Clinical Research Development Unit, Imam Hossein Hospital, Shahid Beheshti University of Medical Sciences, Tehran, Iran (Dr Hosseini Zijoud)

Correspondence and reprint requests to Seyed Reza Hosseini Zijoud, Clinical Research Development Unit, Imam Hossein Hospital, Madani Street, Tehran, Iran. Postal Code: 1617763141 (e-mail: hosseini7sr@ gmail.com). 


\section{REFERENCES}

1. Peeri NC, Shrestha N, Rahman MS, et al. The SARS, MERS and novel coronavirus (COVID-19) epidemics, the newest and biggest global health threats: what lessons have we learned?. Int J Epidemiol. 2020 Feb 22. doi: 10.1093/ije/dyaa033

2. Prompetchara E, Ketloy C, Palaga T. Immune responses in COVID-19 and potential vaccines: lessons learned from SARS and MERS epidemic. Asian Pac J Allergy Immunol. 2020;38:1-9.

3. World Health Organization. Rolling updates on coronavirus disease (COVID-19). https://www.who.int/emergencies/diseases/novel-coronavirus2019/events-as-they-happen. (Accessed March 27, 2020).

4. Worldometer. Confirmed cases and deaths by country, territory, or conveyance. https://www.worldometers.info/coronavirus/\#countries. (Accessed March 27, 2020).
5. Oxford Analytica. COVID-19 impact will be worse than flu. Emerald Expert Briefings. (oxan-es). https://dailybrief.oxan.com/Analysis/ES251195/COVID19-impact-will-be-worse-than-flu. Accessed April 7, 2020.

6. Ahmed SF, Quadeer AA, McKay MR. Preliminary identification of potential vaccine targets for the COVID-19 coronavirus (SARS-CoV-2) based on SARS-CoV immunological studies. Viruses. 2020;12(3): pii: E254.

7. World Health Organization. Coronavirus disease (COVID-19) technical guidance: Infection prevention and control / WASH. https://www.who. int/emergencies/diseases/novel-coronavirus-2019/technical-guidance/infectionprevention-and-control. Accessed April 7, 2020.

8. World Health Organization. Health aspects of biological and chemical weapons. https://www.who.int/csr/delibepidemics/en/allchapspreliminaries_may03. pdf. Accessed April 7, 2020.

9. Borhani M, Khoshzaban F, Jodeiri B, et al. Diet and food in Iranian traditional medicine: hints for further research. Int J Prev Med. 2014;5(11):1480-1481. 